
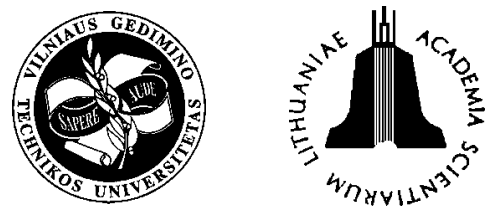

JOURNAL OF CIVIL ENGINEERING AND MANAGEMENT

http:/www.jcem.vgtu.lt

2004, Vol X, No 4, 317-326

\title{
VISUAL VALUE CLARIFICATION - A METHOD FOR AN EFFECTIVE BRIEF
}

\author{
Søren Wandahl \\ Dept of Production, Aalborg University, Fibigerstraede 16, DK 9220 Aalborg East, Denmark. \\ E-mail: sorenw@iprod.aau.dk
}

Received 17 Sept 2004; accepted 8 Nov 2004

\begin{abstract}
The purpose of this research is to explore the processes in the conception of construction projects, ie the brief. More specifically, the intention is to discuss how it can be ensured that the client receives the right product, ie that the real and justified needs of the client and the users are captured, and that they through an iterative process are transformed into building requirements. The research is carried out by a literature study on the briefing process. This reveals that today's briefing process is far from perfect, and a lot of challenges exist. It is when discussed which factors influence the effective briefing process, and a method to facilitate this is proposed. The visual value clarification method is a simple method for supporting the client and the project team in the briefing process. It should help the client recognise his real needs, create a better communication and give the project team a better understanding of the client's needs.
\end{abstract}

Keywords: briefing process, requirements, client needs, effectiveness, values, visualisation.

\section{Introduction}

The well-known management writer Peter F. Drucker [1] once said that the key to business success is doing the right things right. In construction the right things can be different elements depending on the level of abstraction, but in this article the right things are conceived as the product wanted by and fulfilling all needs of the client. Doing things right means the activities in the building process carried out with a minimum use of resources and quality errors. Rationally, a business should first focus on doing the right things and then focus on doing them right; the other way around would be a waste of time and money. According to Drucker [1], a business must start with the customer's realities, his situation, his behaviour, his expectations, and his values. Subsequently, the internal business conditions can be focused on, eg the organisation, production processes, design, calculation, etc.

In a construction project the briefing process is where the project team tries to comprehend what the client wants (the right things) and roughly transform these needs into requirements. In this process a number of hazards can occur [2], among others contextual blindness, which is the tendency to solve a wrong problem through the lack of attention to the primary goal. Unfortunately, the briefing process is not paid much attention, because many people in construction feel that the briefing process is not a problem [3]. Clearly, briefing is both critical to successful construction and yet problematic in its effectiveness. One of the main problems in briefing is that the client is unaware of his needs at this early stage of the building process. As construction progresses, the client may recognise more needs or change his needs, but then it is often too late to make changes according to the designer and the contractor. Barrett \& Stanley [3, p. 3] have a fine description of this problem: "If any attempt is made to change the parameters of the project, as the client's confidence, knowledge and feel for the issue increase, the client is politely reminded of their original statement (...) Not surprisingly the client involved in a project of this sort is often disappointed with the building finally produced (...) a full understanding of the client's real underlying needs has never been allowed to surface. At best the outcome can be efficient, but it stands very little chance of being effective in meeting the client's needs".

The Latham report concludes that more effort is required to understand clients' needs [4], and this view is supported by several other reports and research [eg 5, 6 , 7]. We must, however, be aware that this challenge has two opponents, the client on the one side and the project team on the other. It is well-known that the construction industry often faces a less knowledgeable client, ie one who has no or minor prior experience in this field. Often this kind of client does not understand the structure of the industry, nor does (s)he have an appreciation of the technicalities of buildings [2]. If such a client is not guided carefully, problems are destined to arise. 
The interplay between the client and the delivery team is thus important, and the Johari window, cf. Fig 1, can illustrate this. The client is aware of some of his needs, and some of them are latent. This clearly depends on the client's level of professionalism. The delivery team is also aware of some of the client's needs, but others it have not recognised. The needs known to both the client and the team are illustrated by the open window in the Johari model. Obviously, this window should be as large as possible to achieve the best construction.

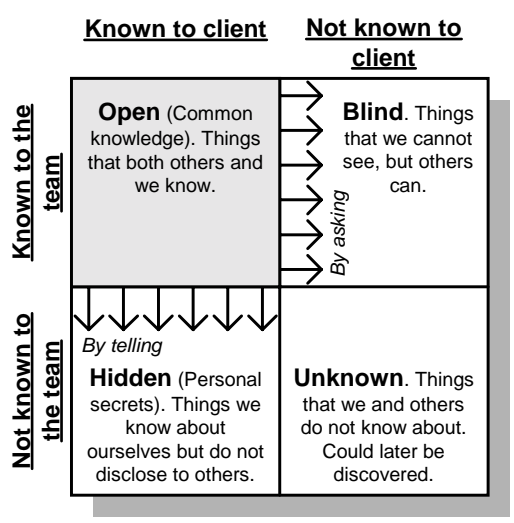

Fig 1. The Johari Window, adapted from [8]

Increasing the open window is evidently an iterative process, since briefing is not a linear process [2]. There are several ways of increasing the open window, and basically, it is about communication between the client and the project team, ie asking and telling. After a short look at the Johari window, it can be concluded that blaming the client for being the key problem in an unsuccessful briefing process is wrong and would over time doom the industry [3]. A successful briefing process is hard to define, and the success of this process can only be evaluated over time. In fact, the level of success should not be measured until well into the use phase.

The assets constructed in a building project have a long-time scale and the decisions about these are, therefore, inherently of a strategic character [9]. There is a time gap between the determination of the needs and the construction of the building containing these requirements, and this further complicates the briefing process.

All in all, there are a lot of challenges in the briefing process, and the term "the briefing challenge" is in this article used as an expression of these challenges. It consists of the following:

- The client is often unaware of his own needs

- Some needs the client does not recognise

- Some needs surface too late, ie after the briefing process has ended

- Some needs are subject to change

- Often the project team cannot effectively transform the needs into requirements
- The importance of the iterative communication process between the team and the client (and users) is often not understood

- Too little attention is paid and too little effort is made.

Another argument for focusing on the briefing process is that the decisions taken in this conceptual phase are of great importance to the following phases [10]. A view of this is illustrated in Fig 2.

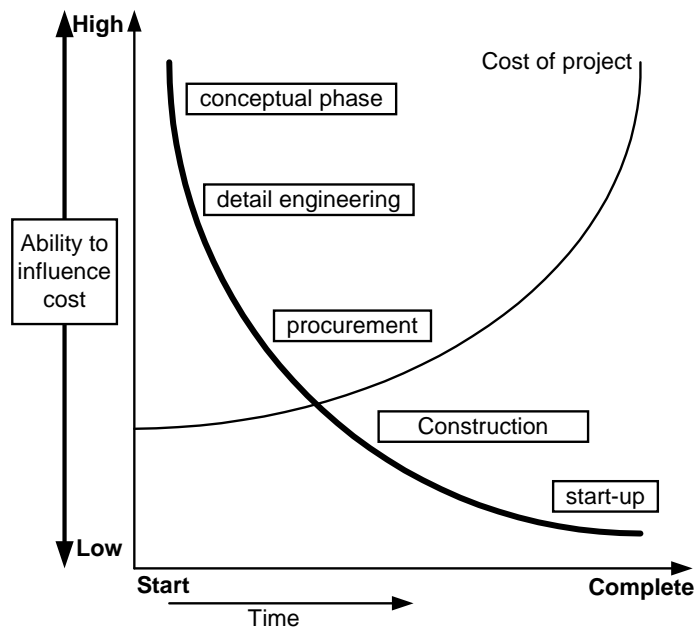

Fig 2. Ability to influence final cost [10]

This is the point of departure for this article, and a method for increasing the effectiveness of the briefing process is, therefore, developed and discussed. This method is called Visual value clarification and is described in short below.

The Visual value clarification method is a pragmatic and visual concept of how to recognise the client's values through interaction and discussion of what is ugly, what is beautiful, what works, etc. The method involves the client, the users if known and either the client's consultant if preparing for a tender or the whole delivery team if working in a partnering mode. Some of the benefits of applying Visual value clarification are directly connected with improving the briefing challenge. Later in this article, the following advantages will be mentioned in more detail. The Visual value clarification method should help ${ }^{1}$ :

- Identify the client's product values, eg his own needs

- Identify the project partners' product values

- Communicate the client requirements to team members

- Establish trust, solidarity and team spirit

- Provide the client with product solutions.

These advantages should help create a more effective briefing process, but there are several elements which affect the effective brief.

${ }^{1}$ It is, however, recognised that the briefing process involves further elements than those pointed out. 
- The client's level of professionalism

- The type of construction, eg size, technology and complexity

- Team communication

- The number of stakeholders (interested parties) in the project

- Time gap between determination of the requirement and construction of the product

- Different types of needs the client may have, the expected, the fundamental and the latent needs.

Therefore, this article will continue with a description of the brief's purpose in the building process and an exploration of some of the elements affecting the effective brief. This is done to ensure that the reader has some knowledge about the dynamics of the briefing process. Following this, the Visual value clarification method will be developed and explained, and, finally, a discussion and a conclusion of how Visual value clarification can help achieve a more effective and efficient briefing process will be presented.

\subsection{Terminology}

Before continuing this article, some important terminology must be explained. It concerns the concepts of effectiveness, efficiency and the definition of product and process values.

\subsubsection{Efficiency and effectiveness}

A model of interested parties is used to explain the difference between efficiency and effectiveness (Fig 3). Attention is drawn to the fact that the model not only addresses the construction client's needs, but all the interested parties' needs [11]. The interested parties' needs should be perceived widely, ie it regards both product and process needs/goals. The objective of stressing all the interested parties' needs is inspired by the Supply Chain Management philosophy as well as the fact that the building industry is heavily fragmented, and that a high level of sub-optimization occurs [6]. If this suboptimization is subjected to a change to super-optimization, the holistic view is needed and, moreover, the

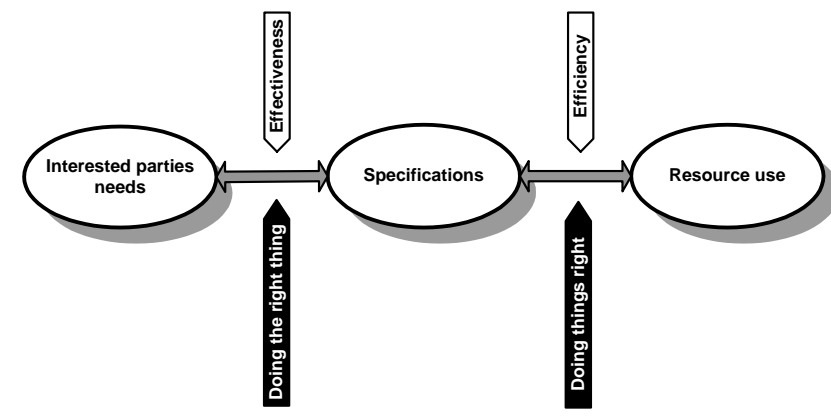

Fig 3. Model of interested parties as a way of explaining efficiency and effectiveness adapted after Bruzelius \& Skärvad [13] holistic view can cause a positive synergy due to greater consensus on how to solve the job [12].

Fig 3 shows the importance of comprehending the difference between efficiency and effectiveness. Effectiveness is an expression of the level of correspondence of the specifications with the interested parties' needs. Efficiency has two dimensions. Firstly, the achieved specifications are compared with the described specifications, and secondly, the production of these specifications is compared with the level of resources used. In other words, effectiveness is doing the right things, and efficiency is doing things right. That is why this article discusses the effective brief.

\subsubsection{Values}

Value is a broad concept and difficult to get a grasp of. In most construction projects the perceived values are developed and described in brief. The achievement of these values, determined by the construction client and sometimes the users, is always the primary objective of a construction project. There are basically two types of the described value; utility value and market value. Utility value is associated with the technical and aesthetic construction and the use of the construction, eg brick type, top lighting, colour, usability, flexibility, etc. Market value is closely connected with the utility value. It describes the value of utility and quality in money and is closely related to demand. In total, the values described in the brief are called product values [14].

Value can besides product values also describe the building process, ie how the cooperation should work. This kind of values is called process value. Examples of process value could be agreement discipline, open communication, keeping of deadlines, mutual respect, etc. The two different kinds of values are illustrated in Fig 4.

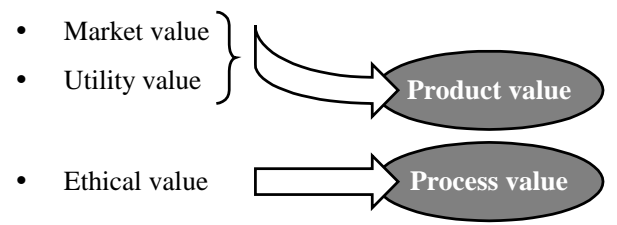

Fig 4. Two different kinds of values

As human beings are different, they tend to think and perceive situations differently. Both product values and process values are, therefore, very subjective. One might say that each individual has his own belief about what is right/wrong and good/bad. This is sometimes referred to as human values [15]. These human values indirectly influence the client's choice of product values and process values.

More in dept reading on human values and its connection to building management can be found in [eg 1618, 19]. 


\section{The brief's purpose in the building process}

A simple illustration of the building process and the transformation of client needs to requirements and product specifications is presented in Fig 5, and afterwards explained.

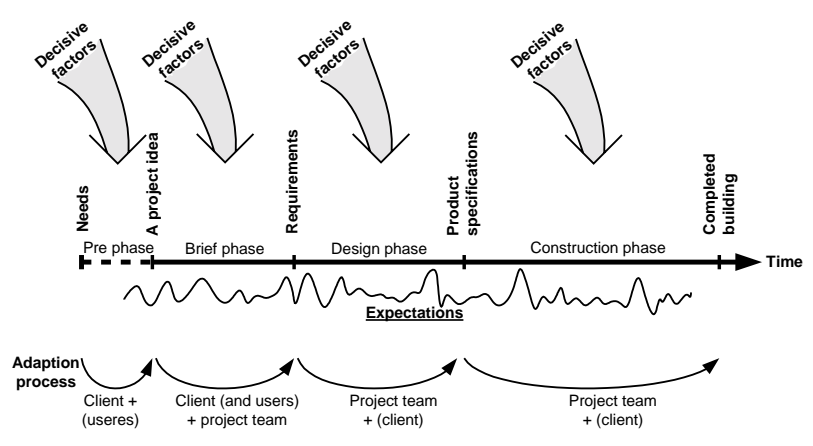

Fig 5. A simple illustration of the building process. It illustrates the transformation of needs to requirements and then further on to product specifications

A coming client has initially some needs, which he works on before considering them as a construction project. When he has worked on and thought appropriately about his needs, he suddenly reaches a state where he considers his needs as an idea for a building project. If the users to some extend are known, they can be coplayers in this adaption process. After this, the actual building process begins with the brief phase. The client's needs should be transformed into building requirements in the briefing process. This implies determination of both product values and process values (see section 1.1.2 in this article). It should, however, be pointed out that this investigation involves primarily the determination of product values. How to determine process values is a subject for other research. In the brief phase the client, user and the project team participate. To which degree the project team participates, depends on which tender mode the client chooses. The end product of the brief phase is a well-worked set of requirements.

According to some literature [20], the client should not participate in the final / detailed design phase and in the construction phase. It is argued that the client has taken all decisions and described them in the requirement. This should give a more efficient design phase, and especially a more efficient construction phase. This might be correct in few simple situations, but mind the passage on making the right things before making things in a right manner. In most situations the client simply cannot realise all his needs in the brief phase, because requirements, both text and illustrations, do not give the same impression as physical bricks and walls. It is, therefore, important to acknowledge that the client will come up with new or changed requirements during the construction phase. However, it is important to make sure that new and changed requirements during the construc- tion phase are kept at a minimum to ensure a high efficiency.

What is relevant in the transformation processes, are the decisive factors. These factors are important for the understanding of especially the briefing process. Examples of decisive factors are:

- Legislation

- Financial capability of the client

- Personal preferences

- Market demand

- Technical opportunities regarding material and equipment

- Trends in society

- ....and more yet unknown factors.

It has been now defined how needs over time are transformed into a project idea and then transformed into requirements, which are transformed into product specifications, which finally are transformed into the finished building. In this process expectations to the final building arise and they may rise and fall during the process. One might say that Fig 5 illustrates the building process as a transformation from a mental non-physical object to a physical product.

\section{Elements affecting the effective brief}

The purpose of the brief is in a wide sense "to comply with the interested parties' reasonable entitled needs" [21]. More precisely, the brief is the elaboration and presentation of client requirements (and other project requirements) [7]. Furthermore, the brief is a communication tool to facilitate dialogue between client and designer and to facilitate the exploration of the possibilities of a project [22].

In the brief the aim of the project should be stated, and the needs should be uncovered and if possible weighed, and the desired quality level should be stated. Moreover, it should be considered if the needs are internally dependent or even conflicting. This involves a range of activities and decisions, which have high impact on the subsequent building process. It is important to come to a decision about the location of the building, aesthetics, fitness for user's purpose, costs, time, technical performance, environmental impact and health \& safety [23]. Many of the decisions taken in the briefing process have long-term consequences. It is, therefore, important with high effectiveness, ie to determine the right product. How can it then be that the briefing process is as problematic as stated in the introduction of this article? It might be because several elements affect the effective briefing process, and also due to the fact that tools to identify client's real needs are missing. These factors are related to the information required, and they include the nature of project, type and size of client, and the skills of those involved in the process [7]. In the following, some of the elements which could affect an effective brief are discussed. 


\subsection{The client's level of professionalism}

In fact, the client does not always get a building which fulfils his expectations. This may be due to financial cuttings in the project, unforeseen occurrences which may lead to an increase in expenses, or if some costs have not been included from the beginning. A proposed solution to this problem is often that the client should be more professional [24]. This viewpoint is supported by many other reports. In [6]: "If the building industry should develop and be more effective and efficient, the role of the construction client should get more professional, and more clients ought to leave their task to a professional client". And in "The Client as a Change Agent" [20] "The client is prospected to have a decisive role in the future building process. He should be the one to lead the building industry's innovation". But what is the underlying idea for proposing this solution? Moreover, most clients are and will still be semi-professionals or amateurs in the building industry.

One point is that only a professional client gains advantage of the repeat-effect, and the increasing knowledge. Inexperienced client organisations also find it relatively difficult to define their requirements in the briefing process [7]. The client should have unilateral focus on what he wants, and not use all his efforts on management of the building process, eg contractual agreements, time and financial management [24]. In general, the whole building and the arrangement of the building industry are quite complicated and hard to get an overview.

\subsection{Size and complexity of the building project}

Not much should be said about this, because the size and complexity of the building project clearly influence the briefing process. For instance, it could be expected that much more attention and alternative tools should be used to identify the client's requirement in a hospital project than in a single family house project. There is certainly a general tendency towards more technical installation in all kinds of building projects, and an increased focus on the briefing process is, therefore, needed.

\subsection{Different types of needs}

As illuminated by the Johari Window, not all the client's needs are explicitly known, neither to the client himself nor to the project team. It is, thus, necessary to differentiate between the client's needs and to understand these different needs. In the eighties the Japanese professor and quality expert Noriaki Kano develops a model for classifying customer requirements [25] with the purpose of achieving as high customer satisfaction as possible. The Kano terminology distinguishes between three different types of product requirements, which influence customer satisfaction [26].
- Must-be requirements. These requirements are basic criteria of a product, which the client takes for granted and does, therefore, often not explicitly demand them. In construction an example of mustbe requirements could be, eg doors and windows, correct sound insulation and plumbing connections. If these requirements are not fulfilled, the client will be extremely dissatisfied. On the other hand, as the client takes the must-be requirements for granted, their fulfilment will not increase his satisfaction dramatically.

- One-dimensional requirements. These requirements are expected by the client and, therefore, explicitly mentioned to the project team. The client's satisfaction is proportional to the level of fulfilment. An example of this could be: roof light, installation of kitchen range, parquet floor, etc.

- Attractive requirements. These requirements have the greatest influence on client satisfaction. However, they are neither explicitly expressed nor expected by the client. If these latent needs are not met, however, there is no feeling of dissatisfaction. General examples of these requirements in construction are hard to provide, but specific context related examples are easier. In a Danish residential building with several apartments, the contractor concludes at the end of the execution phase that the expenses were under budget and he, therefore, decided to provide every apartment with a balcony. This generated high satisfaction among the buyers.

The three different kinds of requirements and their influence on customer satisfaction are illustrated in Fig 6.

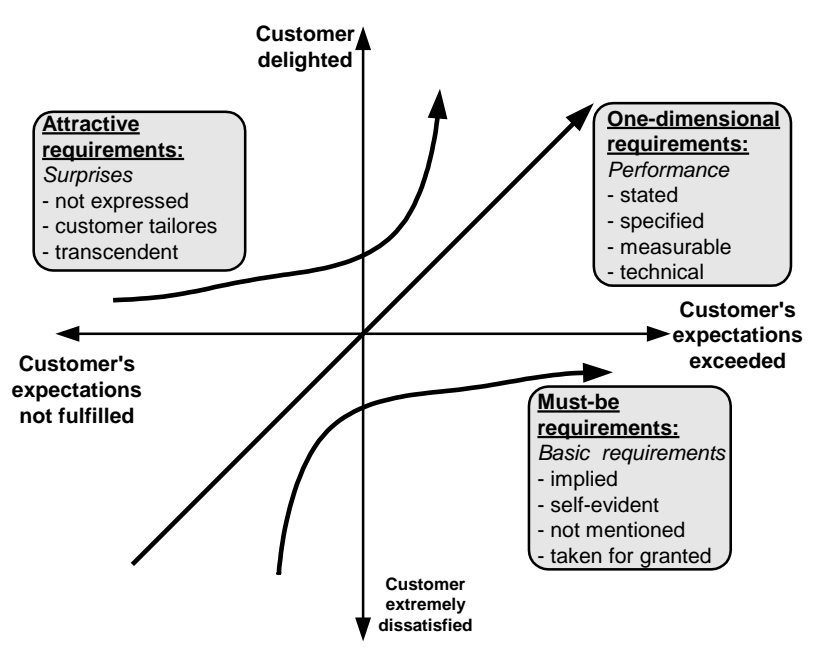

Fig 6. Kano's model in [27] adapted after [28]

What is sometimes seen in construction is that in a design-bid-build tender, the contractor is aware of many must-be requirements, and he can use this knowledge to decrease his bid in the effort of winning and then afterwards inform the client of the "holes" in the tender material and demand an unacceptable high price for these 
must-be requirements. This is of course worst case, instead what often happens, is that the client ends up with a product which does not fulfil his needs, and he will be dissatisfied in different degrees.

In recent years clients frequently choose a designbuild procedure which involves the contractor at an earlier stage than in the design-bid-build tender. The contractor's large knowledge about building in general should then theoretically help fulfil the must-be requirements. Building is often an expensive business, and most clients have tight budgets. If they should have money left over to use for attractive requirements, clearly no money should be used for conflicts and extra yields in the sake of getting must-be requirements right.

The Kano model goes far beyond classification of needs, it also involves a questionnaire and a methodology for calculating the priority of the needs, eg [28], which is not dealt with in this article.

A lot of other elements affect the effective brief, but they are not as important as those mentioned above. This could be communication skills, development of team spirit, capabilities of the participants, etc.

\section{Visual value clarification}

In this part the ideas behind the Visual value clarification method will be explained as well as how the idea appeared and still nurtures.

\subsection{Description of Visual value clarification}

Basically, the Visual value clarification method, VVC, is a very simple and straight-forward idea, where digital cameras are applied to take photos which are used as illustrations of needs. The idea is two-fold; partly to draw attention to the client's needs both to the client himself and to the other project partners, and partly to create a common value set in the project team. The method should help improve some of the elements described in the briefing challenge.

The procedure for applying the VVC can be explained through four steps. All the steps should be arranged as workshops.

1. Compose a team. If the client decides to and has the opportunity ${ }^{2}$ to compose his team in a kind of partnering arrangement, this should be done before working intensively with the brief and applying the VVC method. It is not necessary, although it is of great benefit, to have all the project partners involved in the VVC method. For more information on how to compose the team, the reader is advised to look into partnering articles [eg 29, 30]. If the

\footnotetext{
${ }^{2}$ If the client is public or public financing is involved, he is enforced by legislation to tender, and he cannot select his team as he wishes. The same is valid if the project is of such a size that the European legislation is in use.
}

client cannot or will not involve the whole project team, he can use this method alone or eg together with his consultant. It is still important for the client to realise his needs, and this process can be facilitated through VVC. It must, however, be stated that the VVC will only be of great use if more or less the whole project team participates. If possible, the users of the building should also attend this process. If the users are not known exactly, but the expected pressure groups are known, ie students, senior citizens, etc, these should be involved.

2. Decide on parameters for picture taking. To create consensus among the VVC participants' pictures, it is necessary to agree on around five topics in which they should take pictures. These parameters should continuously be focused on throughout the whole construction process and are thus important for the final building and its use. The parameters could eg be maintenance, comfort and outdoor space.

3. Field trip. The team should then arrange a field trip to one or more finished buildings (trips to sites could also be an option). It is important that the group has access to the exterior of the building as well as the interior. It is recommended to choose publicly well-known buildings to which the participants easily can adopt an attitude. When arranging the field trip, the value parameters should be taken into consideration, ie they should be expressed in the chosen buildings.

4. Communicate values through pictures. Returning from the field trip, the participants should group by profession and together discuss their pictures. Then each profession should select a couple of pictures which best describe their intended values, and they should present these pictures to the team, applying both visual and oral presentation. The goal is not $100 \%$ congruence between the different parties' values. Instead the goal is a common understanding of each others values.

5. The further building process. The team can continue working on communicating and understanding each others values, but at some point the output of the brief must be a building programme. After this, the building process progresses in a "normal" manner with the design phase.

The whole process can be carried out in one to three days, depending on how dedicated the team is. The team and project size will also influence the amount of time used. The following description of experience from a testing of the VVC method can be used as a supplement for understanding it.

\subsection{Perceived benefits of Visual value clarification}

In Fig 7 and in the following text some of the perceived benefits of applying the VVC method as a tool in 
the briefing process are discussed. The benefits are of preliminary conditions due to the fact that the idea has only been tested in one experiment and not on a real construction project.

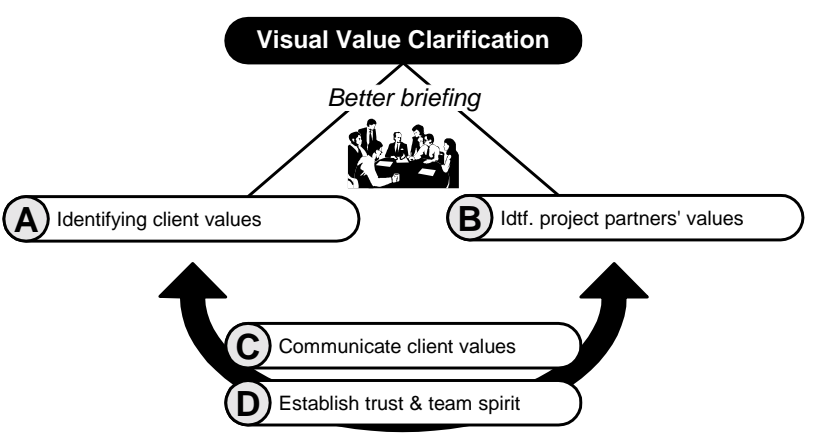

Fig 7. Illustration of benefits obtained by using the Visual value clarification method

A client, particularly first-time client, has difficulties identifying and recognising his own needs. Traditionally, the needs are recognised by applying checklists, questionnaires, etc, but none of these are visual. Humans have seven different kinds of intelligences, all present in each individual, but in different strengths [31]. Some have high mathematical logic or a "good human touch", others are strong in visualising. The point is that we need to apply different kinds of tools to identify client needs, and the VVC method offers a visual approach. By seeing things, humans begin an association process and will often suddenly get an eye-opener experience, eg they recognise (emotional feeling) something they like and would like to have in their building, which they would not have recognized in a non-visual approach. This is illustrated in A and B in Fig 7.

Pictures are also an excellent supplement to text in the effort of communicating needs to the other project participants. We all know that a picture or an illustration often says more than a hundred words. By using pictures as references it is also possible to outline the desired quality level, cf. $\mathrm{C}$ in Fig 7. As this is carried out in workshops, the participants get easier "in touch" with each other, and this is the first step in establishing trust and team spirit.

\subsection{The birth of Visual value clarification}

In the spring 2003, a new Danish building development initiative started, called BYGiNORD (in English: Build-in-the-North, due to its origin in the most northern county of Denmark). The development initiative is founded on three subjects:

1. The user, the professional client and the local government's invitation for tender on the role of the client,

2. Future modes of co-operation in the construction sector,
3. Co-operating supply teams and the future production on the building site.

A group of approximately 75 highly motivated persons from the construction industry are involved in discussions in small groups concerning ideas and methods for improving the building process. These discussions are centred on the participants' everyday problems and their practical knowledge. The initiative was supported and facilitated by a group of researchers in building management from the Department of Production at Aalborg University. More information can be found on the BYGiNORD website, www.byginord.dk, and in [32]. The author of this article is participating in subgroup No 2 and is, furthermore, a member of the BYGiNORD organising committee.

It is within this development initiative, the visual value clarification idea has been developed in interplay between practitioners and university researcher. One of the main contributions came from the architect Mogens Kristensen from the Aarhus Architects, and his original idea can be found in text form in [33]. The idea is still to be full-scale tested on a real construction project, but a group of practitioners are working on final adjustments and preparing for implementation, eg they actively seek a project and a client that will fit the purpose.

\subsection{Experience of the first testing}

In the BYGiNORD development initiative it was decided that it would be appropriate to test the idea before applying it to a real construction project. The purpose was to test whether the idea was operational at all and to validate the intended advantages in the briefing process. The research group arranged a one-day workshop, and an open invitation to all participants in the BYGiNORD initiative was sent out. 15 practitioners from all kinds of professions in the construction industry joined the experiment. The workshop started with a short introduction, and the participants then decided on five value parameters, which should be followed throughout the entire building process and be substantial in the finished construction [34].

- Sun-orientation

- Low maintenance

- Ecology

- Lively rooms

- Opportunity for the user to influence material choice and interior layout.

All the participants were then equipped with a digital camera and grouped by profession. The group then went on an arranged field trip to a recently finished apartment house, which has been heavily commented on in the local media due to its architecture.

After returning from the field trip, the groups: engineer, architect, client, etc discussed the pictures taken. Each group then picked out some of the pictures for 
visual and oral presentation. Finally, a plenum discussion on all the pictures was carried out, and the participants ended up with a better understanding of each others product value, and especially the client's product values.

\subsubsection{The testing results}

An analysis of the values illustrated by pictures including some keywords will always be subjective, but some more or less obvious differences between the pictures do occur. Due to the space limitations of this article, only a few pictures are presented. All the pictures can be found in the BYGiNORD white paper [33].

In general, all the parties took pictures of some of the same elements, both of what they liked and what they disliked. Furthermore, each party also clearly had their own focus area. This is further investigated below.

\subsubsection{Similar focus areas}

All the participants had, not surprisingly, taken similar pictures. Figs 8 and 9 show two elements which all the parties liked and disliked. Firstly, all participants were thrilled by the view from the $18 \mathrm{~m}^{2}$ grand roof terrace. Secondly, none of the participants liked the radiators in the windows. In the local press the apartment building is called the radiator house.

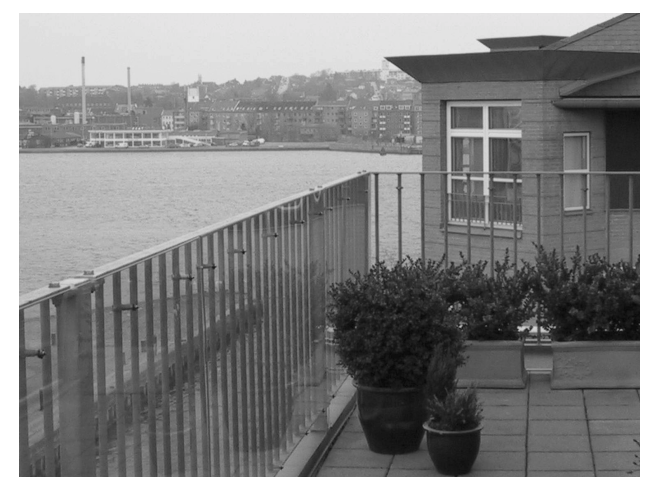

Fig 8. Roof terrace

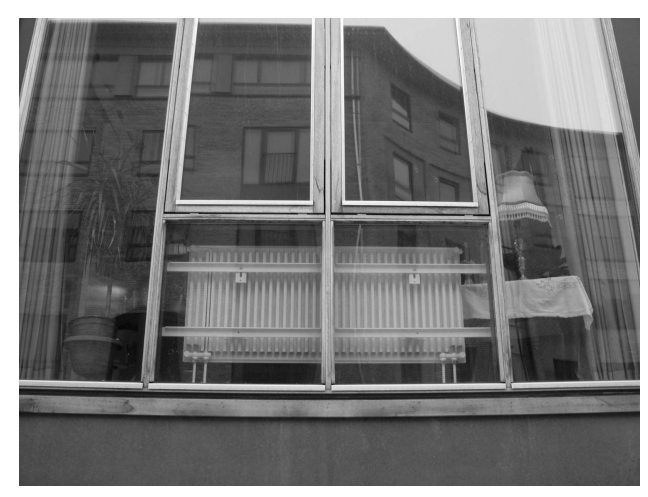

Fig 9. The radiator house

\subsubsection{The parties' own focus areas}

The users immediately focused on the interior and its use and flexibility, along with architecture. They were e.g. interested in the kitchen and the dining area and their opportunity to change the layout. The client had instead his focus on maintenance cost, usability, flexibility and crime preventive arrangements. Especially, usability was in focus. A lot of attention was given to the facilities for elderly and handicapped people. An example of an inappropriate construction is illustrated on Fig 10.

A very high doorstep between the living room and the terrace is not suitable for walking-impaired people. In that sense, the client mainly stressed anti-values.

The architect could not stop taking pictures of architectural details, eg of how the building fitted into the surroundings and architecture in combination with functions of the building. An example is skew fields of vision in the apartments, which increase the run through of sun light.

The engineer was more concerned about technical details such as the use of elements, prefabricated bathroom cabins, etc. The contractor was also interested in details, but the details concerning construction execution.

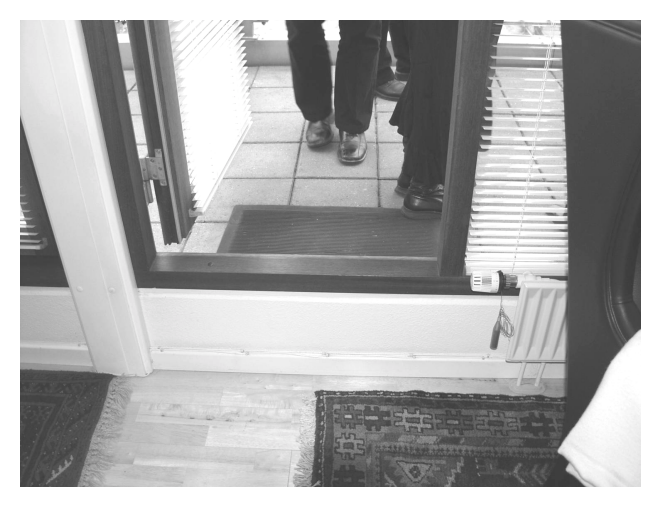

Fig 10. A high doorstep

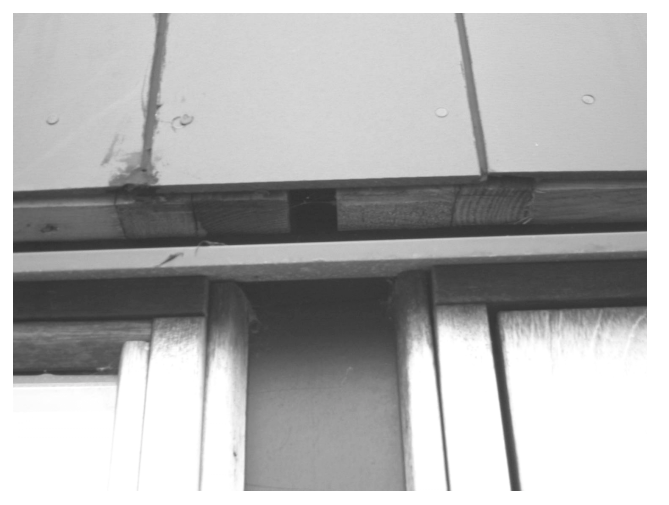

Fig 11. Construction detail 
Fig 11 illustrates a construction detail. The ends of the timber used beneath the surface boards have no sealed endings. A lot of robber lists were also used, and both elements can cause maintenance problems.

The testing conclusion is positive, ie the participating practitioners found the method useful in terms of several areas:

- Getting a better understanding of the client's needs and his product values, eg which solution and materials he likes dislikes;

- Revealing product values of all project members;

- Communicating the client's needs effectively to the other team members;

- Creating a better team spirit and understanding differences between the individuals.

No negative respond was given regarding the method, but surely ideas for minor corrections for the implementation of the idea surfaced.

\section{Conclusion and discussion}

In construction it sometimes occurs that the client is not fully satisfied with the final product delivered. This can be illustrated by a simple equation.

$$
\text { Satisfaction }=\frac{\text { Recieved }}{\text { expected }} \cdot 100 \% \text {. }
$$

What is relevant in this equation, is that the project team can influence both the numerator and the denominator and, thereby, make the clients satisfied with the project. This illustrates indeed the dynamics of the briefing process.

In the briefing process the project team concludes what the client expects or one might say what the client wants. The problem is that the client does not know how to recognise and communicate all his needs and expectations, and the project team does not spend the time and effort needed to ask the client what he expects. When the project is finished, a client will have a built artifact, which (s)he can touch, smell, walk around and see from many different angls. In contrast at the start of the process the client will only have a broad idea of what is wanted and what (s)he are likely to get [3]. This is due to too less attention to the conceptual briefing process, and to what the client really wants. This problem is to some extent discussed in literature, where the main criticism of today's briefing process includes:

- Focus on the wrong problems

- Inappropriate briefing techniques

- Too little iterative communication

- In general not enough focus on this initial phase.

In this article one method for getting closer to the effective brief is proposed, namely the Visual value clarification method. This method is a pragmatic and visual concept of how to recognise the client's needs through interaction and discussion about what is ugly, what is beautiful, what works, etc. Basically, pictures are used as references and illustrations of what the client wants. The underlying idea is that visualisation helps clients (often with no or minor prior experience) recognise their needs, and it also helps the project team identify the requirements better than when only applying textual descriptions. To support this process, it could be useful to use a person as a facilitator. The facilitator could be eg an architect, an engineer or a consultant.

In [3] it is discussed how to obtain a better briefing process in construction. Three main areas are highlighted as important for reaching the effective briefing process:

- Appropriate user involvement

- Appropriate team building

- Appropriate visualisation techniques.

The Visual value clarification method has its main focus on 'appropriate visualisation techniques', but it also touches the other two areas. The client and the final users, if known, are involved in the following manner: they (client + users) are taking pictures of elements, details, buildings, etc illustrating what they like and what they dislike. Furthermore, they present these pictures, accompanied with a talk of what they specifically feel when they see a certain picture. When the project team, including the client and the users, participate on one ore more field trips to buildings, where they can take pictures, the team spirit is strengthened. The field trips could, therefore, be seen as one of several activities used in team building.

In general, more research is needed to understand the dynamics of the briefing process and to make the process effective. It seems that the main part of researchers within building management is more concerned with how to do things right, rather than with what the right things are!

\section{References}

1. Drucker, P. The essential drucker. New York: HarperCollins, 2001. 368 p.

2. Kelly, J.; Morledge, R. and Wilkinson, S. Best value in construction. Oxford: Blackwell Publishing, 2002. 306 p.

3. Barrett, P. and Stanley, C. Better construction briefing. Blackwell Publishing, 1999. 135 p.

4. Latham, S. M. Constructing the team (known as the Latham report). London: HMSO, 1994. $130 \mathrm{p}$.

5. Egan, J. Rethinking construction (UK Construction task force). Dept of Trade and Industry, 1998. 36 p.

6. EBST. The Future of construction - from tradition to innovation (Byggeriets fremtid - fra tradition til innovation). National Agency for Enterprise and Housing, Copenhagen, Denmark, 2000. 192 p. (in Danish).

7. Kamara, J.; Anumba, C. and Evbuomwan, N. Assessing the suitability of current briefing practices in construction within a concurrent engineering framework. International Journal of Project Management, Vol 19, No 6, 2001, p. $337-351$. 
8. Luft, J. Group Process: An introduction to group dynamcs. Palo Alto: Mayfield, 1984. 122 p.

9. Winch, G. Managing construction projects. Oxford: Blackwell Science Ltd., 2002. 456 p.

10. Abdul-Kadir, M. and Price, A. Conceptual phase of construction projects. International Journal of Project Management, Vol 13, No 6, 1995, p. 387-393.

11. Wandahl, S. Value-based management as means for increasing effectiveness and efficiency in construction projects. In: Proc. of CIB2004 World Congress, Toronto, Canada, 2004, p. 213-224.

12. Nielsen, A. and Kristensen, E. Plan Byg - increased effectiveness visualized through a game (Plan Byg Effektivisering af byggeprocessen visualiseret ved pillet). M.Sc. thesis. Aalborg University, Aalborg, Denmark, 2002. 168 p. (in Danish).

13. Bruzelius, L. and Skärvad, P. Integrated organization theory (Integrerad organisationslära). 1989. 341 p. (in Swedish).

14. Wandahl, S. and Bejder, E. Value-based management in the supply chain of construction projects. In: Proc. of the 11th Annual conference on lean construction, Blacksburg, 2003, p. 293-305.

15. Wandahl, S. Value-based cooperation-process controls gains higher product value for everybody (Værdibaseret samarbejde - processtyring skaber højere produktværdier for alle). M Sc thesis. Aalborg University, Denmark, 2002. 168 p. (in Danish).

16. Blanchard, K. and O'Conner, M. Managing by values. San Francisco: Berrett-Koehler publishers, 1997. 154 p.

17. Meglino, B. and Ravlin, E. Individual values in organizations: concepts, controversies and research. Journal of Management, Vol 24, No 3, 1998, p. 351-389.

18. BEC. State of the art-value management Copenhagen: Byggeriets Evalueting Centre, 2003. 36 p.

19. Wandahl, S. Value carriers in a construction project - How different are they? In: Proc. of the 12th annual conference on lean construction, Helsingør, Denmark, 2004, p. 126140 .

20. Bertelsen, S.; Davidsen, H. and Pedersen, K. The Construction Client as Innovation Agent (Bygherren som forandringsagent - på vej mod en ny byggekultur) Copenhagen: Bygherreforeningen i Danmark, 2002. 188 p. (in Danish).

21. Construction Managment 2 - Management of the construction process (Anlægsteknikforeningen. Anlægsteknik 2 -
Styring af byggeprocessen) Copenhagen: Polyteknisk Forlag, 2003. 215 p. (in Danish).

22. Hudson, J. Briefing and design: The role of relativity. RICS Research Foundation, 1999. 7 p.

23. Olsen, W. and Bejder, E. Achieving quality in construction. ACE Program, Danish Conditions. Department of production, Aalborg University, Denmark, 1994. 43 p.

24. EBST. Housing with double value for the users (Huse med dobbelt værdi for bruger). National agency for enterprise and housing, Copenhagen, 2000. 105 p. (in Danish).

25. Kano, N.; Seraku, N.; Takahashi, F. and Tsuji, S.-I. Attractive quality and must-be quality. The Journal of the Japanese Society for Quality Control, Vol 14, No 2, 1984, p. 39-48.

26. Hinterhuber, H.; Matzler, K.; Bailom, F. and Sauerwein, E. The Kano model: How to delight your customers. In: Proc. of the IX international working seminar on production economics. Innsbruck, Austria, 1996, p. 313-327.

27. Matzler, K. and Hinterhuber, H. How to make product development projects more successful by integrating Kano's model of customer satisfaction into quality functional deployment. Technovation, Vol 18, No 1, 1998, p. 25-38.

28. CQMJ. Special edition: Kano's methodes for understanding customer-defined quality. Center for Quality of Management Journal, Vol 2, No 4, 1993, p. 2-37.

29. Bennett, J. and Jayes, S. The seven pillars of partnering. London: Thomas Telford Publishing, 1998. 96 p.

30. EBST. A guide to partnering (Vejledning i partnering). National agency for enterprise and housing, Copenhagen, Denmark, 2004. 62 p. (in Danish).

31. Hauen, F.; Strandgaard, V. and Kastberg, B. The learning organisation (Den Lærende Organisation) Copenhagen: Peter Asschenfeldts nye Forlag a/s, 1998. 293 p. (in Danish).

32. Olsen, W.; Randi, M. E.; Wandahl, S. and Bejder, E. Activation of hidden resources - Experience from a development initiative in a regional area in Denmark. In: Proc of the 12th annual conference on lean construction, Helsingør, Denmark, 2004, p. 885-899.

33. Build-in-the-North (Byginord). www.byginord.dk (in Danish).

34. Kristensen, M. Value-based design (Værdibaseret projektering - oplæg til metode). http://www.byginord.dk/ his torie/materialer/te ma $2 / \mathrm{materialer/}$ Vaerdibaseret\%20projektering.doc, 2004 (in Danish). 